\title{
Thermal degradation behavior and flammability of polyurethanes blended with poly(bispropoxyphosphazene)
}

\author{
Pin-Sheng Wang a, Wen-Yen Chiu b,*, Leo-Wang Chen ${ }^{\mathrm{b}}$, Bar-Long Denq ${ }^{\mathrm{a}}$, \\ Trong-Ming Don ${ }^{\mathrm{c}}$, Yie-Shun Chiu ${ }^{\mathrm{d}}$ \\ ${ }^{a}$ Institute of Material Science and Engineering, National Taiwan University, Taipei, Taiwan, ROC \\ ${ }^{\mathrm{b}}$ Department of Chemical Engineering, National Taiwan University, Taipei, Taiwan, ROC \\ ${ }^{\mathrm{c}}$ Department of Chemical Engineering, Mingchi Institute of Technology, Taipei Shein, Taiwan, ROC \\ ${ }^{\mathrm{d}}$ Chemical System Research Division, Chung Shan Institute of Science and Technology, Taoyuan, Taiwan, ROC
}

Received 11 January 1999; accepted 7 April 1999

\begin{abstract}
Polyurethanes containing different amount of flame retardant, poly(bispropoxyphosphazene), were synthesized by a two-step polymerization. The thermal degradation behaviors of these polyurethanes were then studied by the thermal gravimetric analysis (TGA), TGA coupled with Fourier transform infrared analysis and elemental analysis. A limiting oxygen index was used to evaluate the flammability of these polyurethanes. For these modified polyurethanes under nitrogen, a two-stage thermal degradation behavior was observed. The first stage was caused by the degradation of hard segments, whereas the soft segments were responsible for the second-stage degradation. The thermal degradation activation energies were calculated by using Ozawa's method. It was found that the addition of flame retardant caused a decrease of the activation energy in the first stage, but an increase in the second stage, which was probably due to the formation of a thermal stable structure. As for the flame retardancy, the modified polyurethanes have a higher char yield at $550^{\circ} \mathrm{C}$, and a higher limiting oxygen index than the neat polyurethane. (C) 1999 Elsevier Science Ltd. All rights reserved.
\end{abstract}

Keywords: Polyurethanes; Poly(bispropoxyphosphazene); Flame retardant; Thermal gravimetric analysis; Thermal degradation; Limiting oxygen index

\section{Introduction}

The burning process of polymers generally can be described as three stages: fuel production, ignition and then burning. When a solid polymer was heated with rising temperature, eventually the polymer started to degrade. During the degradation, small molecules were produced in which the combustible compounds were evaporated and mixed with air, forming a flammable mixture. When the concentration of this mixture and also the temperature reached the flammability limits, it started to burn. The exothermic heat from the burning process fed back to the condensed phase, causing further degradation of the polymer [1].

In order to stop or retard the burning process, generally flame retardants are added to the polymers. A

* Corresponding author. variety of mechanisms such as gas-phase retardation, condensed-phase retardation and dissipation of combustion heat [2-6] can achieve the retardation. In gas-phase retardation, the concentration of oxygen in the gas phase is diluted by the liberation of inert gas from the burning of the flame retardant. Therefore, the flame is retarded or inhibited. The inert gas includes $\mathrm{N}_{2}, \mathrm{CO}_{2}$, etc. The other route, through gas-phase retardation, is to produce trapping agents that can capture the free radicals, especially the active $\mathrm{H}$. and $\mathrm{OH}$. In condensed-phase retardation, the flame retardant is able to increase distinctly the conversion of organic matter to char during burning, which thus decreases the amount of flammable volatile gases reaching the flame zone and reduces the heat transfer from the flame to the polymer. The dissipation of combustion heat, it is achieved generally by the endothermic reaction and/or liberation of water from the flame retardant at high temperatures. In this way, it is able to keep polymers from further degradation. 
The flame retardants in the market include halogencontaining compounds, halogen-antimony compounds, phosphorous compounds and hydrated inorganic compounds. Among them, the phosphorous compounds have the advantage in that they generally give off non-toxic and non-corrosive volatile combustion products. In studies using phosphorous compounds as flame retardants in polyurethanes, most researchers believed that the mechanism is mainly condensed-phase retardation [7-16]. Backus et al. [7] reported that most of the phosphorus in the flame retardant was left in the char. After thermal degradation of a foamed polyurethane containing phosphorous compound, Einhorn and Michelson [8] found that the amount of char was increased which can be attributed to the formation of involatile acid compounds from the thermal degradation of phosphorous compounds. Papa and Proops [9] found that the thermal stability of polyurethanes was decreased with the addition of phosphorous flame retardants. Grassie and Scott [10] studied the thermal degradation behavior and mechanism of polyurethanes from 4,4'-diphenylmethane diisocyanate and 1,4-butanediol. With the addition of poly(ammonium phosphate), the degradation of polyurethane was accelerated due to the formation of phosphoric acid which further converted the butanediol to tetrahydrofuran by dehydration. In addition, the phosphoric acid could also crosslink with carbodiimide and form a brown stable solid on the surface. Therefore, the char yield was increased and the remaining polyurethane was able to avoid further degradation. By chemical bonding of phosphorus onto polyol, Grassie and Mackerron [11-13] were able to synthesize a series of polyurethanes with different amount of phosphorus and studied their thermal degradation mechanisms and products. Chang et al. [14-16], in another way, synthesized polyurethanes with chain extenders containing phosphorus. They also found that the thermal degradation occurred earlier than that of pure polyurethane. In addition, it also promoted the dehydratin reaction and increased the char yield.

It has been shown that the use of flame retardants containing both phosphorus and nitrogen could lead to the synergism in the flame retardancy. As a result, the amount of additive can be decreased. Therefore, we synthesized a series of polyurethanes with the addition of poly(bispropoxyphosphazene), LFR. In a separate paper [17], we have found that LFR could accelerate the urethane reactions and, furthermore, took part in the reactions that resulted in the formation of micro-crosslinks. Yet, as the reactions proceeded to a certain extent, the flame retardant began to precipitate out as a second dispersed phase. In this paper, we are going to report the thermal degradation behavior, identification of degradation products both in gas phase and condensed phase, and the flammability of LFR-modified polyurethanes.

\section{Experimental}

\subsection{Synthesis}

All the materials have been described in a separate paper [17], in which, the chemical structure of the flame retardant LFR, poly(bispropoxyphosphazene), is indicated:<smiles>CCOP(C)(C)(N=[V])OCC</smiles>

All the polyurethane (PU) samples were synthesized by a two-step polymerization. An isocyanate-terminated prepolymer was obtained first from the reaction of 4,4'-diphenylmethane diisocyanate (MDI) with poly(tetramethylene oxide) oligomer, PTMO 1000. The prepolymer was then added with a homogeneous mixture of 1,4butanediol (1,4-BD) with LFR. The ratio of $\mathrm{NCO} / \mathrm{OH}$ was 1.04. After thorough mixing, the mixture was removed to a mold at $70^{\circ} \mathrm{C}$ for $100 \mathrm{~min}$, followed by $2 \mathrm{~h}$ at $100^{\circ} \mathrm{C}$. The detailed procedures and the recipe of $\mathrm{PU}$ samples are described in Wang et al. [17].

\subsection{Analysis of thermal degradation behavior}

The thermal degradation behavior of the LFR-modified PU was investigated using a Perkin-Elmer TGA7 thermal gravimetric analysis at various heating rates under nitrogen and air atmosphere, respectively. The evolved gas products of the modified PU at various temperatures were analyzed using a SEIKO TG/DTA 220 TGA coupled with BIO-RAD Fourier transform infrared (FTIR), FTS-7, at a heating rate of $10^{\circ} \mathrm{C}$ $\mathrm{min}^{-1}$. The residuals at various temperatures in TGA were investigated using BIO-RAD FTIR, FTS-40. Two parts of residuals were mixed with 100 parts of $\mathrm{KBr}$ powder. After grinding, the powder was pressed into a transparency disc. The recorded wave-number range was $400-4000 \mathrm{~cm}^{-1}$ and 32 spectra were averaged to reduce the noise. In addition, an Elemental Analyzer, CHN-O Rapid EA from Heraeus Company, was used to analyze the various element contents of residuals at different temperatures during the thermal degradation.

\subsection{Flammability}

A limiting oxygen index (LOI) value was used to evaluate the flammability of modified PU samples. LOI values were measured using an Oxygen Index Tester (Custom Scientific Instruments Inc., NJ, USA), following ASTM Standard D2863 method. 


\section{Results and discussion}

\subsection{Thermal degradation behavior under $\mathrm{N}_{2}$}

Fig. 1 shows the TGA curves of various samples at a heating of $10^{\circ} \mathrm{C} \min ^{-1}$ under $\mathrm{N}_{2}$. It was found that the thermal degradation of LFR occurred $120^{\circ} \mathrm{C}$ earlier than that of neat PU (PUOF). The gas discharge during the thermal degradation of LFR was proved to be propylene by TGA-FTIR analysis in agreement with the previous result [17]. As the amount of LFR additive increased, the modified PU began to degrade earlier and earlier; and the two-stage degradation behavior became more obvious. Table 1 shows all the calculated results: the on-set degradation temperature $\left(T_{\text {on }}\right)$, maximum-rate degradation temperature $\left(T_{\max }\right)$ and their maximum rate $\left(R_{\max }\right)$ of the various samples. It can be seen from Table 1 that $T_{\max }$ in the first stage decreased with the addition of LFR flame retardant, whereas the $T_{\max }$ in the second stage only decreased to a certain extent. Thus, the addition of LFR could accelerate the first-stage degradation of PU. As a result, the flame retardancy could be achieved in advance with the addition of LFR in PU, if LFR could fully develop its function as a flame retardant. Table 1 also shows that the char yield $\left(Y_{\mathrm{c}}\right)$ at $550^{\circ} \mathrm{C}$ increased with the addition of LFR, but a linear

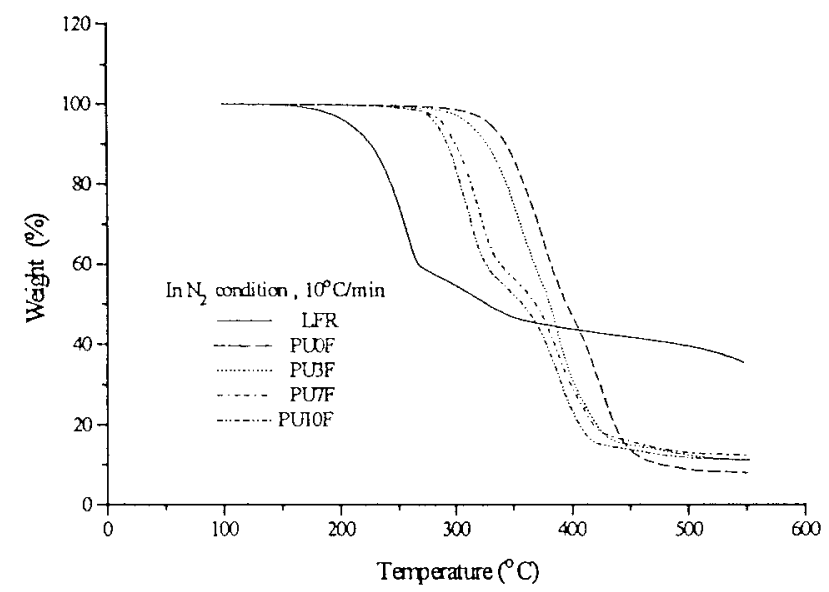

Fig. 1. The TGA curves of various samples at a heating rate of $10^{\circ} \mathrm{C}$ $\min ^{-1}$ under $\mathrm{N}_{2}$. relationship was not observed with the amount of LFR additive. If the heating rate was changed from $10^{\circ} \mathrm{C}$

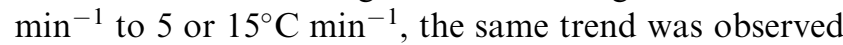
for all the samples (results not shown here).

The relationship between weight loss fraction $(\alpha)$ and apparent activation energy $(E \alpha)$ can be determined by using Ozawa's method [18,19]. First, every sample was heated at different heating rates $(\beta)$ to obtain the thermal degradation curves; and then their logarithm of heating rate $(\log \beta)$ were plotted with reciprocal of temperature $(1 / T)$ at some certain $\alpha$ values. The activation energies thus can be calculated from the slopes of these lines. Table 2 lists all the apparent activation energies at different conversions for various samples. Among these, there seems no change in activation energies with the conversion for the samples LFR (up to 50\%) and PU0F, whose average values are 107 and $133 \mathrm{~kJ} \mathrm{~mol}^{-1}$, respectively. As LFR was added to PU, the activation energies in the first-stage degradation were decreased, yet they were increased in the second stage. These findings strongly support the results from Grassie and Scott [10] that the thermal degradation of PU was accelerated by the dehydration initiated by the LFR degradation products. At a later stage of degradation, the activation energies were increased probably due to the formation of thermal stable compounds like the brown crystalline solid from the reaction of carbodiimide with polyphosphoric acid which were produced from the earlier stage of LFR degradation.

\subsection{Thermal degradation behavior under air}

Fig. 2 shows the TGA curves of various samples at $10^{\circ} \mathrm{C}$ min $^{-1}$ heating rate under air atmosphere. Compared with the TGA results in $\mathrm{N}_{2}$, the weight loss fraction was less for both the neat and modified PU at high temperatures. With the addition of LFR, modified PU started to degrade at lower temperatures in air than those in $\mathrm{N}_{2}$. In other words, under air atmosphere, the modified PU developed their flame retardancy earlier than that in nitrogen. Finally, the char yield at $550^{\circ} \mathrm{C}$ was also higher for those PU undergoing degradation in air.

Table 1

The calculated results from TGA curves of various samples under $\mathrm{N}_{2}{ }^{\mathrm{a}}$

\begin{tabular}{|c|c|c|c|c|c|c|}
\hline Samples & $T_{\text {on }}\left({ }^{\circ} \mathrm{C}\right)$ & $T_{1 \max }\left({ }^{\circ} \mathrm{C}\right)$ & $R_{1 \max }\left(\% \min ^{-1}\right)$ & $T_{2 \max }\left({ }^{\circ} \mathrm{C}\right)$ & $R_{2 \max }\left(\% \min ^{-1}\right)$ & $Y_{\mathrm{c}}(\%)$ \\
\hline LFR & 207 & 256 & 4.6 & 319 & 0.9 & 35.5 \\
\hline PU0F & 329 & 374 & 4.5 & 424 & 4.0 & 8.1 \\
\hline PU3F & 311 & 354 & 4.1 & 387 & 5.1 & 11.1 \\
\hline PU7F & 288 & 321 & 4.9 & 389 & 3.6 & 12.4 \\
\hline PU10F & 282 & 312 & 5.7 & 388 & 3.7 & 11.3 \\
\hline
\end{tabular}

a The heating rate was $10^{\circ} \mathrm{C} \min ^{-1} ; T_{\text {on }}$, was the on-set degradation temperature; $T_{1 \max }$, and $T_{2 \max }$ were the maximum-rate degradation temperatures in the first stage and second stage, respectively; $R_{1 \max }$, and $R_{2 \max }$ were the maximum rates in the first stage and second stage, respectively; $Y_{\mathrm{c}}$ was the char yield at $550^{\circ} \mathrm{C}$. 


\subsection{TGA/FTIR analysis of pyrolysis gas products}

\subsubsection{Neat $P U$}

The identification of pyrolysis gas products during thermal degradation was accomplished by TGA coupled with FTIR. Fig. 3 shows the pyrolysis gas flow curves of PU0F and PU10F under $\mathrm{N}_{2}$. It can be seen that both samples had two stages of degradation, yet both of them occurred earlier for PU10F. For PU0F, the pyrolysis gas product in the first stage was mainly carbon dioxide (Fig. 4) by computer data base analysis; whereas the main gas stream in the second stage was butyl ether (Fig. 5). Petrovic et al. [20] pointed out that the early stage degradation occurred mainly in the hard segments for the polyether-type (such as PTMO) polyurethanes. Grassie et al. [21] studied the thermal degradation of PU composed of purely hard segments (MDI + 1,4-BD) and proposed a detailed thermal degradation mechanism. In their mechanism, urethane groups first undergo depolycondensation, resulting in individual monomers, which then further react to produce carbon dioxide. Therefore, we believed that there were two stages in thermal degradation of neat PU: the first stage was caused by the

Table 2

The apparent activation energies at different conversions for various samples under thermal degradation in $\mathrm{N}_{2}$

Sample Activation energy, $E \alpha$, by Ozawa's method $\left(\mathrm{kJ} \mathrm{mol}^{-1}\right)$

\begin{tabular}{|c|c|c|c|c|c|c|c|c|c|c|}
\hline & \multicolumn{10}{|c|}{ Conversion, $\alpha^{\mathrm{a}}$} \\
\hline & 0.10 & 0.20 & 0.30 & 0.40 & 0.45 & 0.50 & 0.55 & 0.60 & 0.70 & 0.80 \\
\hline LFR & 105 & 108 & 114 & 114 & 95 & 108 & - & - & - & - \\
\hline PU0F & 131 & 136 & 135 & 131 & 129 & 129 & 131 & 135 & 139 & 132 \\
\hline PU3F & 114 & 115 & 116 & 122 & 125 & 137 & 143 & 146 & 149 & 159 \\
\hline PU7F & 105 & 108 & 113 & 112 & 117 & 134 & 138 & 138 & 130 & 117 \\
\hline PU10F & 110 & 123 & 124 & 118 & 118 & 136 & 153 & 160 & 159 & 122 \\
\hline
\end{tabular}

a $\alpha=[100-$ residual weight $(\%)$ in TGA $] / 100$.

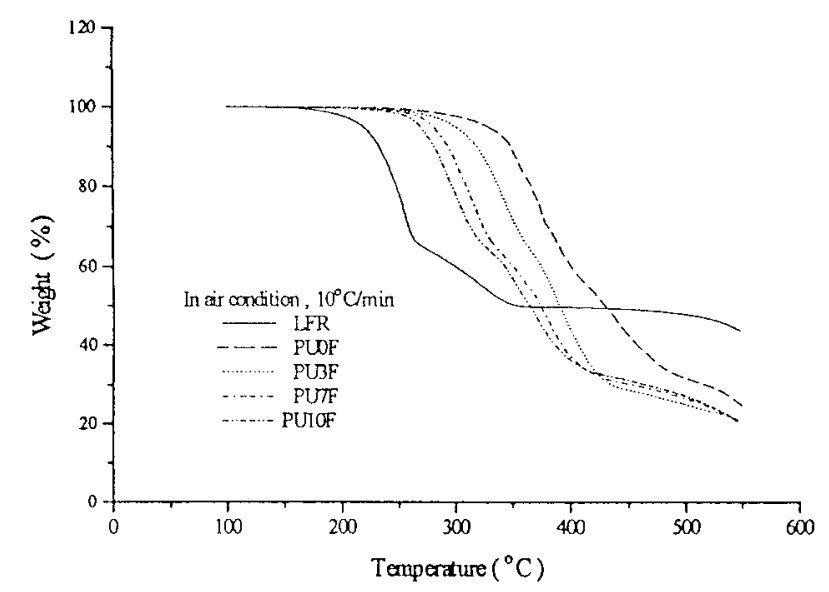

Fig. 2. The TGA curves of various samples at a heating rate of $10^{\circ} \mathrm{C}$ $\min ^{-1}$ under air. degradation of hard segments; and the degradation of soft PTMO segments was responsible for the second stage.

\subsubsection{LFR-modified $P U$}

For PU10F, tetrahydrofuran (THF) was found in the first-stage degradation, in addition to $\mathrm{CO}_{2}$ (Fig. 6). However, in the second stage, only THF was observed in the degradation products, as shown in Fig. 7. Grassie et al. [10] investigated the thermal degradation mechanism of PU (MDI + 1,4-BD) with the addition of poly(ammonium phosphate). They found that during thermal degradation, poly(phosphoric acid) was produced, which caused the dehydration of 1,4-BD to THF and a browning thermal stable residual in the condensed phase as well. Our findings are in agreement with their results. Therefore, THF, produced in the first-stage degradation, was from the dehydration of 1,4-BD initiated by the LFR additive; whereas the THF, produced in the second stage, was mainly from the breaking of the ether bond $(\mathrm{C}-\mathrm{O}-\mathrm{C})$ in PTMO. It must be pointed out that the water vapor produced from the dehydration could not only dilute the combustible gas mixture, but also cool down the environmental temperature. As a result, the flame retardancy was achieved.

\subsection{FTIR analysis of pyrolysis products in condensed phase}

\subsubsection{Neat $P U$}

Fig. 8 shows FTIR spectra of thermal degradation products in condensed phase for neat PU at various temperatures under $\mathrm{N}_{2}$, compared with that at room temperature. Those at 290,325 and $375^{\circ} \mathrm{C}$ were in the range of first-stage degradation, and that at $425^{\circ} \mathrm{C}$ belonged to the second-stage degradation. It can be seen

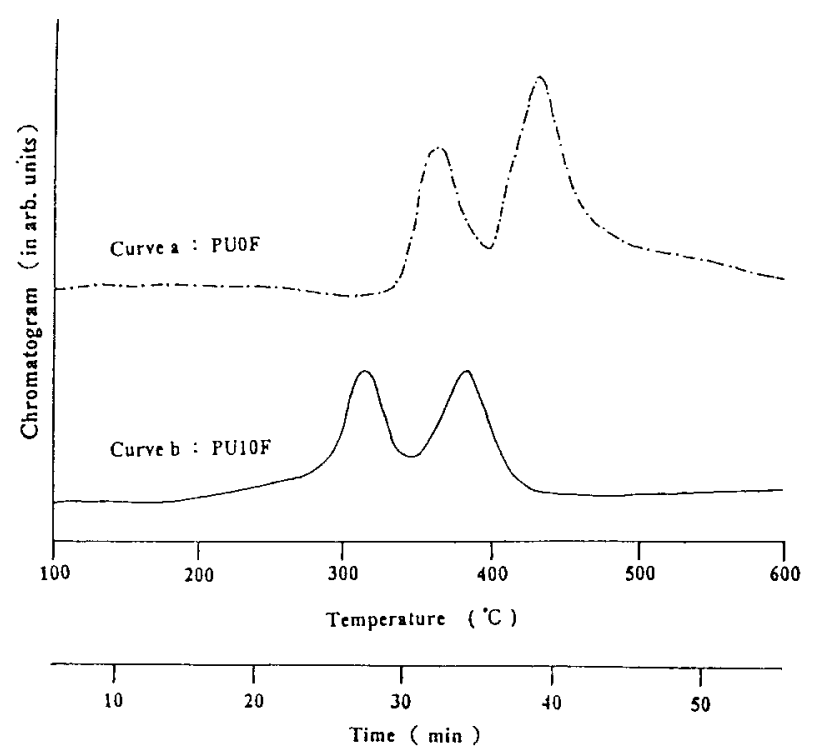

Fig. 3. The discharge gas flow curves of PU0F and PU10F under thermal degradation in $\mathrm{N}_{2}$. 


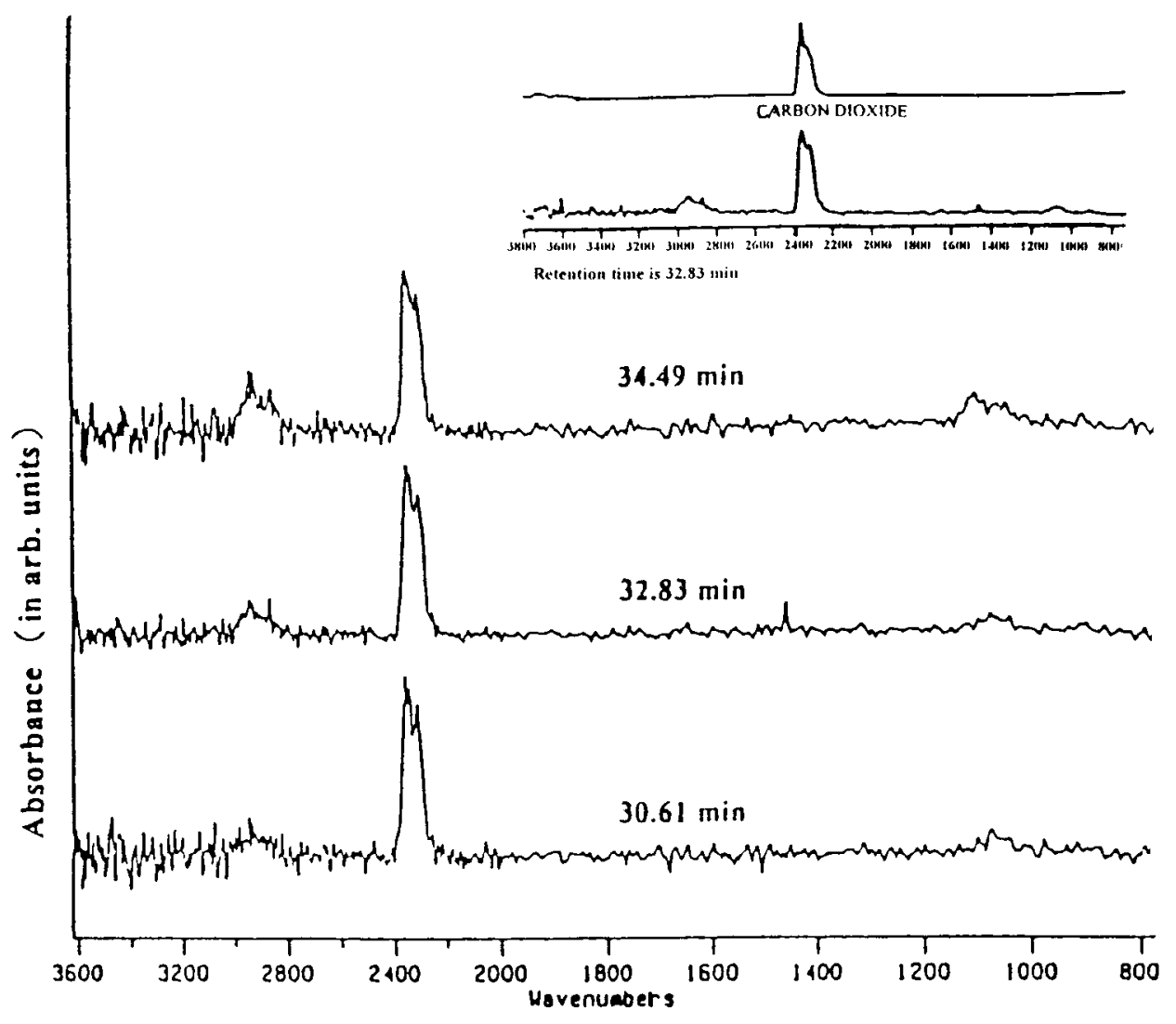

Fig. 4. FTIR spectra of gas products in the first-stage degradation of PU0F sample.

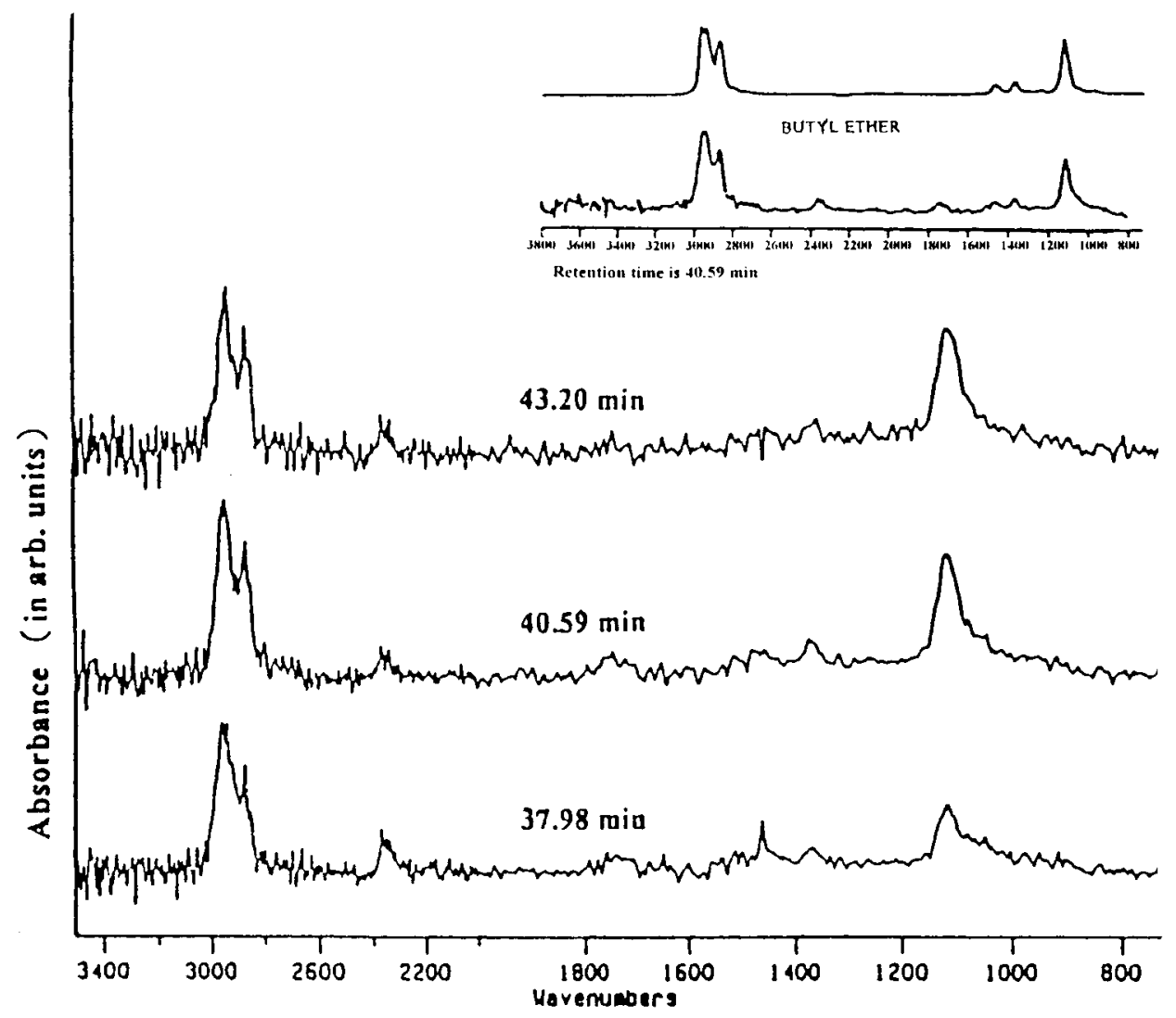

Fig. 5. FTIR spectra of gas products in the second-stage degradation of PU0F sample. 


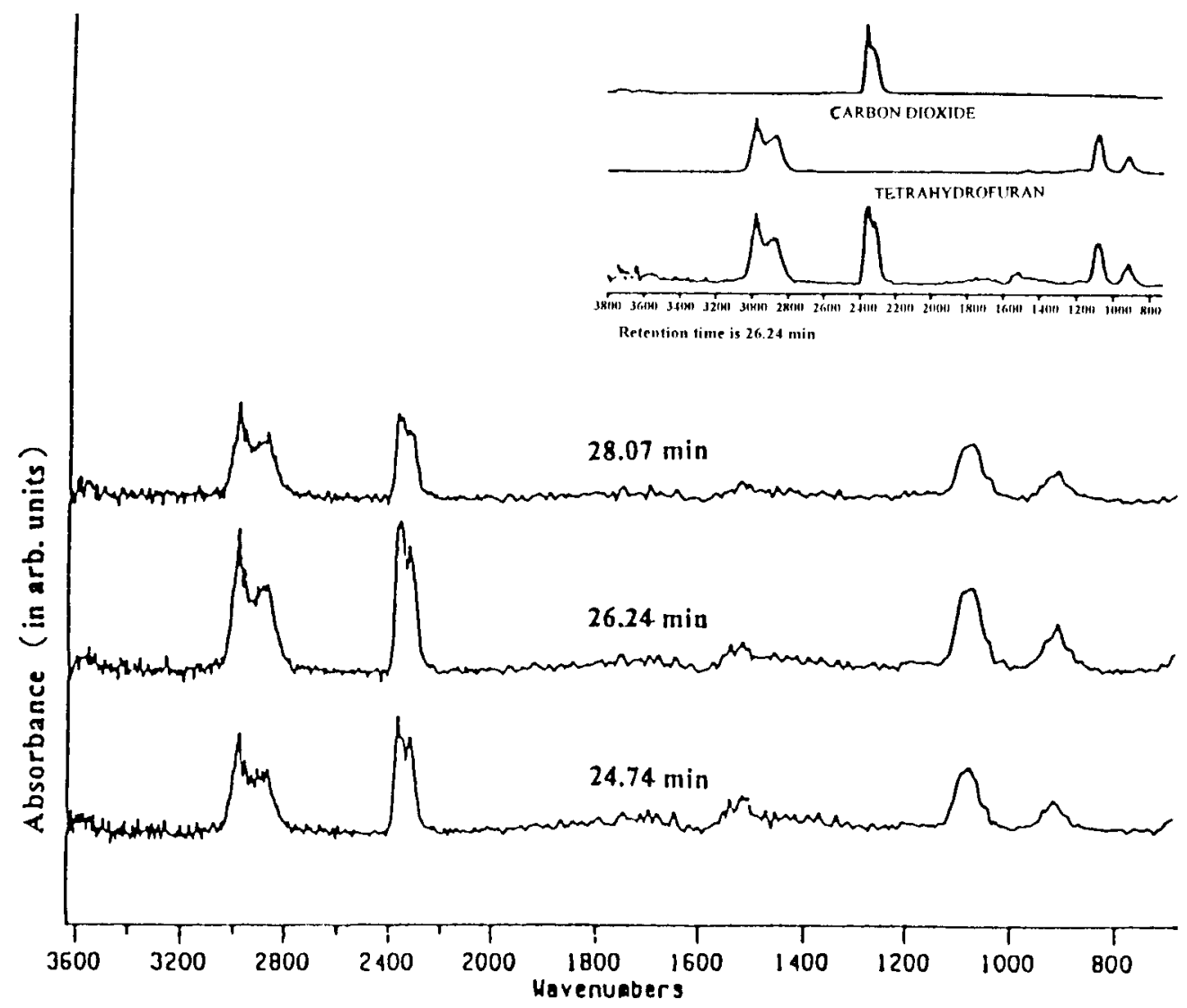

Fig. 6. FTIR spectra of gas products in the first-stage degradation of PU10F sample.

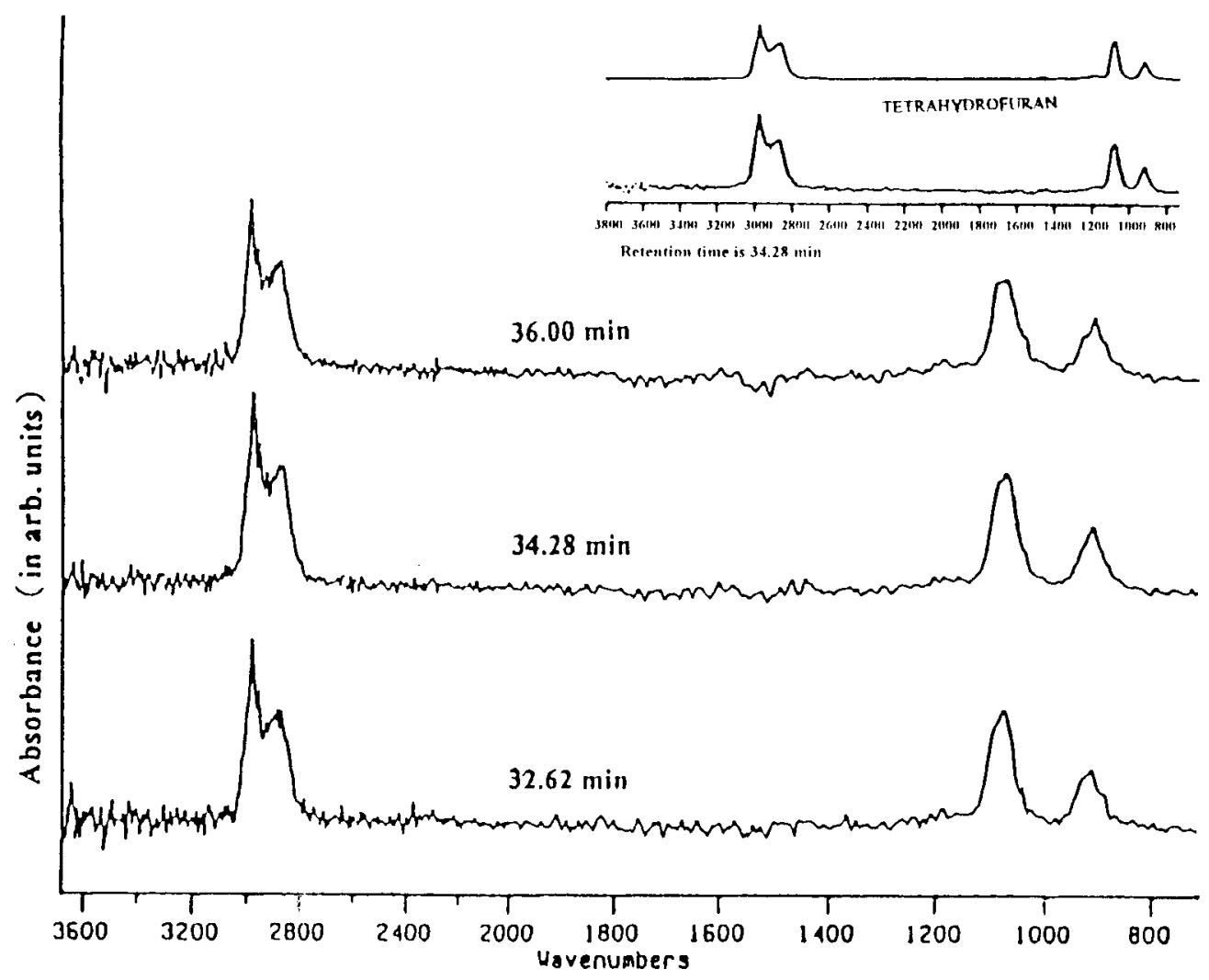

Fig. 7. FTIR spectra of gas products in the second-stage degradation of PU10F sample. 
that the characteristic absorption peaks of urethane groups from 1680 to $1740 \mathrm{~cm}^{-1}(\mathrm{C}=\mathrm{O}$ stretching) gradually decreased in intensity with an increase in temperature. They completely disappeared at $425^{\circ} \mathrm{C}$. Also, the C $-\mathrm{N}$ absorption peak at $1230 \mathrm{~cm}^{-1}$ decreased with the increasing temperature. Yet, the $\mathrm{C}-\mathrm{O}-\mathrm{C}$ absorption peak in PTMO soft segments did not decrease until the temperature was as high as $425^{\circ} \mathrm{C}$. This again validated that the first-stage degradation was from the hard segments and the second stage was caused by the PTMO soft segments. In addition, several new peaks appeared during thermal degradation: the peak at $3400 \mathrm{~cm}^{-1}$ was attributed to the stretching absorption of $\mathrm{N}-\mathrm{H}$ groups and $1640 \mathrm{~cm}^{-1}$ peak was from the stretching of $\mathrm{C}=\mathrm{O}$ in urea groups. This indicates that some urea compounds were formed during the thermal degradation of PU.

\subsubsection{LFR-modified $P U$}

When LFR was added to $\mathrm{PU}$, the $\mathrm{C}=\mathrm{O}$ absorption peaks in the range of $1680 \sim 1740 \mathrm{~cm}^{-1}$ and $\mathrm{C}-\mathrm{N}$ peak at $1230 \mathrm{~cm}^{-1}$ both from the urethane groups had already disappeared at $325^{\circ} \mathrm{C}$ (Fig. 9). The characteristic absorption peak of ether groups started to decrease at temperature higher than $325^{\circ} \mathrm{C}$. At high temperatures,

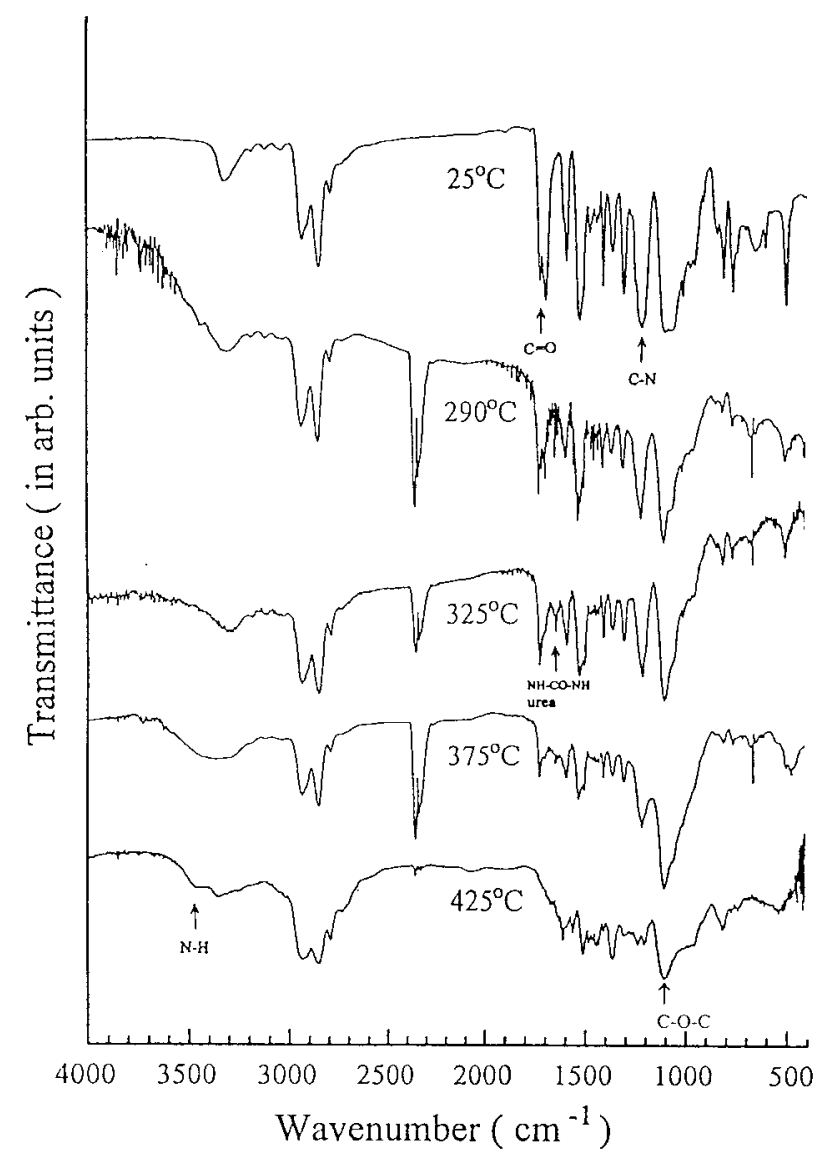

Fig. 8. FTIR spectra of thermal degradation products in condensed phase of PUOF at various temperatures under $\mathrm{N}_{2}$. several new bands appeared including $\mathrm{N}-\mathrm{H}$ absorption at $3400 \mathrm{~cm}^{-1}$ and $\mathrm{P}-\mathrm{O}-\mathrm{P}$ stretching absorption in the range of $980 \sim 990 \mathrm{~cm}^{-1}$. Fig. 10 shows FTIR spectra of residuals at $550^{\circ} \mathrm{C}$ of PU0F and PU10F. Apparently, the $\mathrm{P}-\mathrm{O}-\mathrm{P}$ absorption peak was observed only in the sample PU10F.

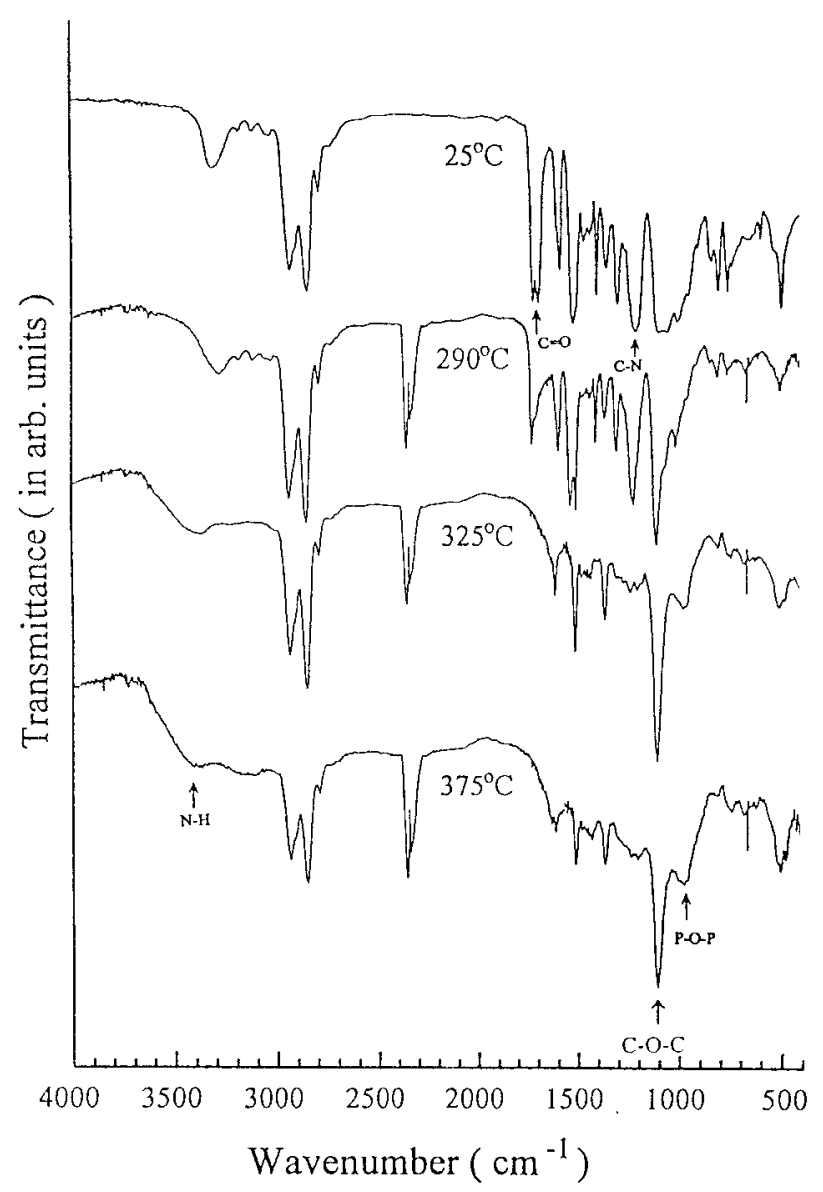

Fig. 9. FTIR spectra of thermal degradation products in condensed phase of PU10F at various temperatures under $\mathrm{N}_{2}$.

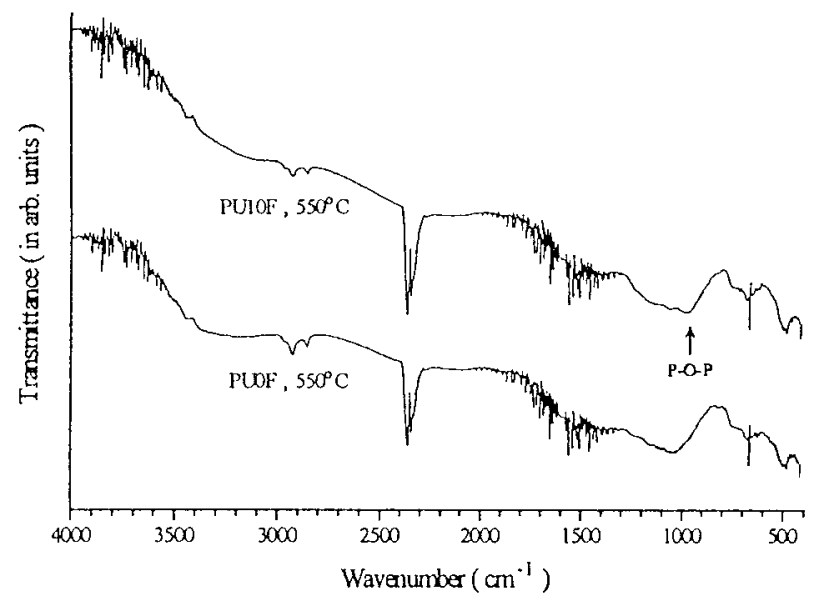

Fig. 10. FTIR spectra of residuals at $550^{\circ} \mathrm{C}$ of PU0F and PU10F under $\mathrm{N}_{2}$. 
Therefore, phosphoric acid or poly(phosphoric acid) was formed during the thermal degradation of LFR. These phosphoric acid compounds not only promote the dehydration reaction but also react with other residuals to form thermal stable compounds left in the remainder.

Under air atmosphere, almost the same pyrolysis products in condensed phase were observed for PU and modified PU as those in $\mathrm{N}_{2}$ (results are not shown here).

\subsection{Elemental analysis of condensed phase}

An Elemental Analyzer was used to determine the element contents in PU0F and PU10F such as C, H, N and $\mathrm{O}$ in residuals at 290,325 and $375^{\circ} \mathrm{C}$ compared with the values at $25^{\circ} \mathrm{C}$. With the knowledge of $\mathrm{C}, \mathrm{H}, \mathrm{N}$ and $\mathrm{O}$ contents, the phosphorus content can thus be calculated by subtraction. For PU0F, 290, 325 and $375^{\circ} \mathrm{C}$ were in the range of first-stage degradation. Yet, $375^{\circ} \mathrm{C}$ was at the second-stage degradation for PU10F. From the elemental analysis results, we further calculated the ratio, $R$, of individual element content at high temperatures to its original content at $25^{\circ} \mathrm{C}$. These ratios are listed in Tables 3 and 4 for samples PU0F and PU10F, respectively. Obviously, most elements were lost from condensed phase faster for the LFR-modified PU, indicating the LFR additive accelerated the degradation of PU. It also can

Table 3

The conversions and the elemental analyses results of PU0F at various temperatures

\begin{tabular}{llllll}
\hline${ }^{\circ} \mathrm{C}$ & Conversion $\alpha^{\mathrm{a}}$ & \multicolumn{4}{l}{ Ratio $\left(R^{\mathrm{b}}\right)$} \\
\cline { 3 - 6 } & & $\mathrm{C}$ & $\mathrm{H}$ & $\mathrm{N}$ & $\mathrm{O}$ \\
\hline 25 & 0.00 & 1.00 & 1.00 & 1.00 & 1.00 \\
290 & 0.01 & 0.98 & 0.98 & 0.99 & 1.02 \\
325 & 0.04 & 0.97 & 0.96 & 0.99 & 0.92 \\
375 & 0.34 & 0.68 & 0.70 & 0.62 & 0.60 \\
\hline \multicolumn{2}{l}{$\mathrm{a} \alpha=[100-$ residual weight (\%) of TGA $] / 100}$. \\
b $R=$ (the individual element content at high temperatures)/(original \\
content at room temperature).
\end{tabular}

Table 4

The conversions and the elemental analyses results of PU10F at various temperatures

\begin{tabular}{llllll}
\hline${ }^{\circ} \mathrm{C}$ & Conversion $\alpha^{\mathrm{a}}$ & \multicolumn{5}{l}{ Ratio $\left(R^{\mathrm{b}}\right)$} \\
\cline { 3 - 6 } & & $\mathrm{C}$ & $\mathrm{H}$ & $\mathrm{N}$ & $\mathrm{O}$ \\
\hline 25 & 0.00 & 1.00 & 1.00 & 1.00 & 1.00 \\
290 & 0.09 & 0.88 & 0.90 & 1.08 & 0.82 \\
325 & 0.40 & 0.60 & 0.64 & 0.76 & 0.44 \\
375 & 0.58 & 0.41 & 0.42 & 0.47 & 0.32 \\
\hline
\end{tabular}

a $\alpha=[100-$ residual weight ( $\%$ ) of TGA $] / 100$.

b $R=$ (the individual element content at high temperatures)/(original content at room temperature). be seen from Fig. 11 that the phosphorus element remained exclusively in the condensed phase during the thermal degradation.

\subsection{Flammability}

Table 5 lists the LOI values for various samples. The values in the left column were from the test following ASTM D2863 and those in the right column were measured using powder sample as in Nail et al. [22]. For PU0F, the LOI value by ASTM method was apparently higher than that from powder samples. This is because in ASTM method, the candle-like flame was generally taken away with the dripping since the method required the sample sheet to be held vertically [15]. As a result, a high oxygen concentration was required to keep the specimen burning continuously for $3 \mathrm{~min}$, consequently giving a higher LOI value. Nevertheless, it can be seen from Table 5 that the addition of LFR is advantageous to increase the flame retardancy of PU. In addition, only 3 phr LFR (equivalent phosphorus content is 0.67 $\mathrm{wt} \%$ ) already had the same level of flame retardancy as that at least $1.5 \mathrm{wt} \%$ of phosphorus content is required for the traditional phosphorous compounds. This is because LFR has both phosphorus and nitrogen elements which can give the synergism in flame retardancy.

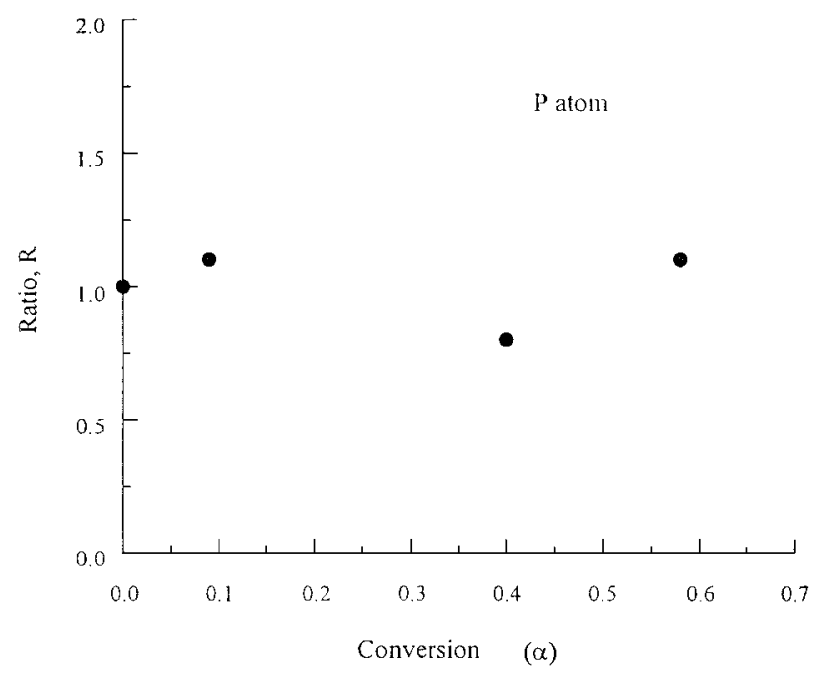

Fig. 11. The ratio of phosphorus content in condensed phase at different conversions to its original content for a PU10F sample.

Table 5

The limiting oxygen index values of various samples

\begin{tabular}{lll}
\hline Sample & ASTM D2863 & Powder test \\
\hline PU0F & 25 & 18.4 \\
PU3F & 26 & - \\
PU7F & 26 & - \\
PU10F & 27 & 27.0 \\
\hline
\end{tabular}




\section{Conclusions}

Under $\mathrm{N}_{2}$ atmosphere, a two-stage degradation behavior was observed for a neat polyurethane and also for LFR-modified polyurethanes. The addition of LFR flame retardant accelerated the thermal degradation of PU and increased the char yield at $550^{\circ} \mathrm{C}$.

The apparent activation energies during thermal degradation were calculated by using Ozawa's method. The addition of LFR decreased the activation energies of PU in the first-stage degradation, yet increased the second-stage activation energies.

After the analysis of pyrolysis products in gas phase as well as in condensed phase, we believed that the degradation of PU in the first stage was mainly from the hard segments, whereas the degradation of soft segments was responsible for the second-stage degradation. The degradation products of the LFR flame retardant initiated the dehydration reaction, which could have effects on both the dilution of combustible gas mixture and a decrease in the surrounding temperature.

In flammability, the addition of LFR could increase the LOI value of PU, thus increasing the flame retardancy of PU.

\section{Acknowledgements}

The authors would like to thank Chung Shan Institute of Science and Technology (CSIST), Taiwan, ROC for their financial support.

\section{References}

1 Gamino G, Costa L, Cortemiglia MP. Polym Degrad Stab 1991;33:131

2 Fish A, Franklin NH, Pollard RT. J Appl Chem (London) 1961;13:506

3 Thrune RI. ACS Organic Coatings and Plastics Chemistry Preprints 1963;23(1):15.

4 Eichiorn J. J Appl Polym Sci 1964;8:2497.

5 Khanna YR, Pearce EM. In: Lewin M, Atlas SM, Pearce EM, editors. Flame-Retardant Polymeric Materials, vol. 2. New York: Plenum Press, 1978. p. 43-61.

6 Pitts JJ. J Fire and Flammability 1972;3:51.

7 Backus JK, Darr WC, Gemeinhardt PG, Saunders JH. J Cell Plast 1965;1:178.

8 Einhorn IN, Michelson RW. ACS Organic Coatings and Plastics Chemistry Preprints 1968;28(1):15.

9 Papa AJ, Proops WR. J Appl Polym Sci 1972;16:2361.

10 Grassie N, Scott G. Polymer Degradation and Stability. Cambridge, UK: Cambridge University Press, 1985 [Chapter 6].

11 Grassie N, Mackerron DH. Europ Polym J 1980;16:113.

12 Grassie N, Mackerron DH. Polym Degrad Stab 1983;5:43.

13 Grassie N, Mackerron DH. Polym Degrad Stab 1983;5:89.

14 Chang TC, Shen WY, Chiu YS, Chen HB, Ho SY. J Polym Res 1994;1:353.

15 Chang TC, Chiu YS, Chen HB, Ho SY. Polym Degrad Stab 1995; 47:375.

16 Chang TC, Shen WY, Chiu YS, Ho SY. Polym Degrad Stab 1995;49:353.

17 Wang P-S, Chiu W-Y, Don T-M. Polym Degrad Stab 1999;66:233.

18 Ozawa T. Bull Chem Soc Jpn 1965;38:1881.

19 Doyle CD. J Appl Polym Sci 1961;5:285.

20 Petrovic ZS, Zavargo Z, Flynn JH, Macknight WJ. J Appl Polym Sci 1994;51:1087.

21 Grassie N, Zulfiqar M. J Polym Sci, Polym Chem Ed 1978;16:1563.

22 Reghunadhan Nair CP, Clouet G, Guilbert Y. Polym Degrad Stab 1989;26:305. 